\title{
(6) OPEN ACCESS \\ Tackling risky alcohol consumption in sport: a cluster randomised controlled trial of an alcohol management intervention with community football clubs
}

\author{
Melanie Kingsland, ${ }^{1,2}$ Luke Wolfenden, ${ }^{1,2}$ Jennifer Tindall, ${ }^{2}$ Bosco C Rowland, ${ }_{1}^{3}$ \\ Christophe Lecathelinais, ${ }^{2}$ Karen E Gillham, ${ }^{2}$ Pennie Dodds, ${ }^{1}$ Maree N Sidey, ${ }_{1}{ }^{3}$ \\ John C Rogerson, ${ }^{4}$ Patrick McElduff, ${ }^{1}$ lan Crundall, ${ }^{4}$ John H Wiggers ${ }^{1,2}$
}

${ }^{1}$ School of Medicine and Public Health, the University of Newcastle, Callaghan, New South Wales, Australia ${ }^{2}$ Hunter New England Population Health, Wallsend New South Wales, Australia ${ }^{3}$ School of Psychology, Deakin University, Burwood, Victoria, Australia

${ }^{4}$ Australian Drug Foundation, Melbourne, Victoria, Australia

\section{Correspondence to}

Melanie Kingsland, Hunter New England Population Health, Locked Bag 10, Wallsend, NSW 2287, Australia; melanie.kingsland@ hnehealth.nsw.gov.au

Received 22 September 2014 Revised 18 February 2015

Accepted 11 May 2015 Published Online First 2 June 2015

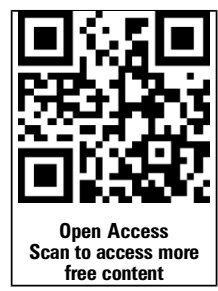

\section{CrossMark}

To cite: Kingsland $M$, Wolfenden L, Tindall J, et al. J Epidemiol Community Health 2015:69:993-999.

\section{ABSTRACT}

Background An increased prevalence of risky alcohol consumption and alcohol-related harm has been reported for members of sporting groups and at sporting venues compared with non-sporting populations. While sports clubs and venues represent opportune settings to implement strategies to reduce such risks, no controlled trials have been reported. The purpose of the study was to examine the effectiveness of an alcohol management intervention in reducing risky alcohol consumption and the risk of alcohol-related harm among community football club members.

Method A cluster randomised controlled trial of an alcohol management intervention was undertaken with non-elite, community football clubs and their members in New South Wales, Australia. Risky alcohol consumption (5+ drinks) at the club and risk of alcoholrelated harm using the Alcohol Use Disorders Identification Test (AUDIT) were measured at baseline and postintervention.

Results Eighty-eight clubs participated in the trial ( $n=43$, Intervention; $n=45$, Control) and separate crosssectional samples of club members completed the baseline ( $N=1411)$ and postintervention $(N=1143)$ surveys. Postintervention, a significantly lower proportion of intervention club members reported: risky alcohol consumption at the club (Intervention: 19\%; Control: 24\%; OR: 0.63 (95\% Cl 0.40 to 1.00); $p=0.05)$; risk of alcohol-related harm (Intervention: 38\%; Control: 45\%; OR: 0.58 (95\% Cl 0.38 to 0.87); $p<0.01)$; alcohol consumption risk (Intervention: 47\%; Control: 55\%; OR: 0.60 (95\% Cl 0.41 to 0.87$) ; p<0.01$ ) and possible alcohol dependence (Intervention: 1\%; Control: 4\%; OR: 0.20 (95\% Cl 0.06 to 0.65$) ; p<0.01)$.

Conclusions With large numbers of people worldwide playing, watching and sports officiating, enhancing clubbased alcohol management interventions could make a substantial contribution to reducing the burden of alcohol misuse in communities.

Trial registration number ACTRN12609000224224.

\section{INTRODUCTION}

Worldwide, excessive alcohol consumption is responsible for $5.9 \%$ of deaths and $5.1 \%$ of the global burden of disease. ${ }^{1}$ High levels of alcoholrelated harm and risky alcohol consumption occur among both male and female fans and players of a range of sports, particularly team and contact sports. $^{2-5}$ In the USA, up to three times the number of alcohol-related arrests are reported to occur on college football game days compared to equivalent non-game days and public holidays, ${ }^{2}$ while in Australia, non-elite football players have been reported to consume between 4 and 9 times the recommended level of alcohol ${ }^{6}$ per drinking session, ${ }^{3}$ with similar findings among footballers in Ireland $^{4}$ and Brazil. ${ }^{5}$

With 270 million people globally involved in football (association soccer) alone ${ }^{7}$ and large proportions of people (28-36\%) involved in organised sports, ${ }^{8} 9$ sporting clubs provide an opportune setting to reduce the risk of alcohol-related harm in the community. Despite a number of sports organisations implementing alcohol management policies to reduce the risk of alcohol-related harm at sporting events, ${ }^{10} 11$ sporting clubs and sport venues have failed to implement evidence-based alcohol management practices comprehensively and consistently. ${ }^{11} 12$ In addition, limited rigorous scientific evidence exists to support the effectiveness of such initiatives. For example, recently published systematic reviews of sport and alcohol-focused controlled trials failed to identify any interventions that sought to modify the alcohol management practices of sport clubs. ${ }^{13-15}$ Nonetheless, a small number of non-controlled trials in this setting have reported promising results. A single group prepost evaluation of an intervention to introduce light-and midstrength beer and targeted alcohol bans in an amateur football competition reported reductions in alcohol sales and alcohol-related antisocial behaviour, ${ }^{16}$ while a cross-sectional study, involving a range of Australian sporting clubs, reported a significant inverse association between the prevalence of risky alcohol consumption and the implementation of a multistrategic alcohol management programme. ${ }^{17}$ There is also evidence to suggest such alcohol management strategies are acceptable to the sporting club's management. ${ }^{18}$

Prohibiting free or cheap alcohol promotions, ${ }^{19} 20$ ceasing drinking games, ${ }^{21}$ prohibiting the sale of alcohol via roaming sale in stands ${ }^{22}$ and restricting/ceasing alcohol-related sponsorship ${ }^{23}$ have been identified as potentially effective strategies in reducing risky alcohol consumption and alcohol-related harm in sports clubs. In addition, 
reviews of interventions in other premises licensed to sell alcohol, such as clubs, pubs, bars and nightclubs, suggest that alcohol management strategies are effective in reducing risky alcohol consumption and subsequent alcohol-related harm. ${ }^{24} 25$ Specifically, differential pricing and availability of alcoholic drinks based on alcohol content, ${ }^{24}{ }^{25}$ enforcement of responsible service of alcohol policies and practices ${ }^{24} 25$ and restrictions on the hours/days of alcohol sales ${ }^{2425}$ have been found to be effective.

It remains to be established if interventions incorporating alcohol management strategies are effective in reducing risky alcohol consumption and risk of alcohol-related harm among sporting club members. To address this gap in evidence, a study was undertaken to examine the effectiveness of a multistrategic alcohol management intervention in community football clubs in reducing: (1) risky alcohol consumption at the club, and (2) risk of overall alcohol-related harm among club members.

\section{METHODS}

\section{Trial registration and protocol}

Australian New Zealand Clinical Trials Registry, ACTRN12609000224224. Publication of research protocol. ${ }^{26}$

\section{Design}

A repeat cross-sectional cluster randomised controlled trial was undertaken with community football clubs (clusters) randomised to either control or intervention groups.

\section{Setting}

The study was undertaken with community football clubs within the Hunter, New England and Sydney regions of New South Wales, Australia.

Table 1 Intervention strategies by accreditation level

$\begin{array}{ll}\text { Accreditation } & \text { Intervention strategy* } \\ \text { level } & \text { Legislative liquor licencing requirements satisfied in } \\ \text { Legards to signage, staff training, alcohol-service hours } \\ \text { and areas, licensee presence and water provision } \\ \text { Intoxicated people are not permitted to enter, are not } \\ \text { served alcohol and are not permitted to remain in the } \\ \text { club } \\ \text { - Alcohol sold at the club is only consumed at the club } \\ \text { - Alcoholic drinks are only served in standard drink } \\ \text { measures } \\ \text { - Club maintains a register of alcohol-related incidents } \\ \text { - Level 1, plus: } \\ \text { - Bar servers do not consume alcohol } \\ \text { Substantial food is provided when alcohol is served } \\ \text { Non-alcoholic drinks and low-alcoholic drinks are } \\ \text { available and are cheaper than full-strength alcoholic } \\ \text { drinks } \\ \text { - Club does not serve 'shots' or double-nips of alcohol or } \\ \text { sell ready-to-drink products over } 5 \% \text { alcohol/volume } \\ \text { - Club does not conduct drinking games/promotions that } \\ \text { encourage risky alcohol consumption or provide cheap } \\ \text { drinks } \\ \text { - Levels 1 and 2, plus: } \\ \text { - Club has some sponsorship that is not from the alcohol } \\ \text { industry } \\ \text { - Club has developed a written alcohol management } \\ \text { policy and distributed it to members }\end{array}$

${ }^{*}$ Further detail regarding the intervention is available in the study protocol. ${ }^{26}$

\section{Participant eligibility and recruitment}

Clubs

All community level, non-elite 'football' clubs (Rugby League, Rugby Union, soccer/association football and Australian Rules football) within the study area were eligible to participate if they had over 40 members, sold alcohol and were not participating in an alcohol management improvement programme. A nominated representative (eg, President) from each club was telephoned to assess club eligibility and invite clubs to participate in the study.

\section{Club members}

A quasi-random process was used to select club members for baseline and postintervention surveys, with a study invitation provided to the 30 members of each club with the most recent birthdays. ${ }^{27}$ Members of clubs (players, spectators/fans, coaches/ trainers, committee members or administrators) were eligible to participate in the study if they were $18+$ years of age and spoke English. Selected members were telephoned to confirm eligibility and to obtain formal consent. Each club was provided AU $\$ 500$ to reimburse member recruit costs.

\section{Random allocation and blinding}

Following baseline data collection, clubs were randomly allocated (using a Microsoft Excel random-number generator) to intervention or control conditions using simple randomisation in a 1:1 ratio, stratified by football code and geographical area. Randomisation was performed by an independent statistician not involved in intervention delivery or data collection. Research staff involved in postintervention data collection were blind to the group allocation of clubs. To assess blinding, staff were asked to report which treatment group they believed the club members belonged.

\section{Intervention}

The intervention was based on an existing alcohol management intervention (Good Sports) in community sports clubs. ${ }^{28}$ To maximise effectiveness, the intervention addressed multiple determinants of risky alcohol consumption, including alcohol availability and pricing, ${ }^{24} 25$ free alcohol promotions, ${ }^{19} 20$ drinking games $^{21}$ and alcohol-related sponsorship. ${ }^{23}$ The alcohol management practices were organised into a three-level accreditation framework, implemented over two and a half sporting seasons (2010-2012; table 1).

\section{Intervention implementation strategies}

Based on a capacity building model, ${ }^{29}$ the following strategies were utilised to support club implementation of the intervention alcohol management practices: project officer support, ${ }^{30}$ implementation cost recovery, ${ }^{31}$ accreditation and merchandise, ${ }^{32}$ printed resources and newsletters, ${ }^{30}{ }^{33}$ feedback from observational audits of alcohol management practices at game days, ${ }^{34}$ training ${ }^{33}$ and letters of support from state sporting organisations. ${ }^{31}$

\section{Control group}

Control and intervention club members received printed resources on topics unrelated to the trial.

\section{Data collection procedures and measures}

Computer-assisted telephone surveys were conducted with club members from both groups at baseline (6 months preintervention, June-August 2009) and immediately postintervention (July-October 2012). Survey scripts were pilot-tested prior to use. 
Primary outcome

Risky alcohol consumption at sporting clubs

Alcohol consumption at sporting clubs was assessed using a graduated frequency index, which measured the frequency (everyday; 5-6 days/week; 3-4 days/week; 1-2 days/week; 23 days/month; 1 day/month; less often; or never) that a club member reported consuming specified quantities of alcohol (20 or more; $11-19 ; 7-10 ; 5-6 ; 3-4$; and 1-2 standard drinks) at their club over the past 3 months. ${ }^{35}$ Risky alcohol consumption was defined as consuming five or more drinks on one occasion. ${ }^{6}$ The proportion of members who reported risky alcohol consumption at least once a month was reported.

The protocol for the trial proposed the use of a 7-day diary to collect data on alcohol consumption at sporting clubs; ${ }^{26}$ however, at baseline, it was apparent that participating members only attended their club once every 2 weeks when the club hosted a 'home' game. As a result, such data were missing for a large $(\sim 50 \%)$ proportion of the sample and consequently, not included in the assessment of study outcomes.

\section{Secondary outcome}

\section{Risk of overall alcohol-related harm}

The Alcohol Use Disorders Identification Test (AUDIT) was used to measure risk of alcohol-related harm. Median AUDIT score was reported and a score of 8 and above was used to categorise members as consuming alcohol at risky or high-risk levels. ${ }^{36}$ For the AUDIT subscales, increased risk of alcoholrelated harm was defined as: (1) an alcohol consumption score of 6 or more (items $1-3$ ); (2) a dependency score of 4 or more (items 4-6); (3) an alcohol-related problems score of 1 or more (items $7-10){ }^{36}$

\section{Club characteristics}

Club representatives provided information on club size (number of players and members), football code and postcode. Project data were used to report the level of intervention accreditation reached by each club.

\section{Statistical analysis}

Descriptive statistics were used to describe club and member characteristics, with Postcode used to classify clubs as 'major city' or 'inner/outer regional' (regional/rural). $\chi^{2}$ analysis was used to assess any differences between consenting and nonconsenting clubs; Fisher's Exact and Wilcoxon tests were used to assess for bias in clubs lost to follow-up across the two treatment groups; and descriptive statistics were used to describe the outcome of blinding research staff.

Intention-to-treat analyses were undertaken using logistic regression for categorical outcomes and linear regression for continuous outcomes. Between-group differences in AUDIT scores (intervention vs control) were assessed through interaction of group and time. Analysis was undertaken at the club member level using a Generalised Estimating Equations framework to adjust for the clustering of members within clubs. ${ }^{37}$ The same method of analysis was used to describe the primary outcome intervention effect by football code and club location. A sensitivity analysis was performed to test for any bias due to missing data, with missing post-intervention data imputed by carrying forward data collected for the club at baseline. The results of this analysis are reported when they differed from those of the main analysis. Descriptive statistics are used to report outcome measures for those clubs that implemented the entire intervention according to protocol (achieved level three accreditation).

The $\alpha$-value for all significance testing was 0.05 , SAS (V.9.2).

\section{Sample size and power calculations}

Data previously collected by the research team indicated that the prevalence of risky alcohol consumption at sporting clubs was $27 \%$. Based on these figures and allowing for an intraclass correlation of 0.18 , it was determined that 35 clubs per experimental group (with at least 19 members per club) would provide the study with $80 \%$ power to detect a $13 \%$ difference in the prevalence of risky consumption. It was also calculated that 35 clubs per group would provide the study with $80 \%$ power to detect: a $15 \%$ difference in prevalence of total AUDIT scores $\geq 8$; a $14 \%$ difference in prevalence of AUDIT consumption subscale scores $\geq 6$; a $5 \%$ difference in prevalence of AUDIT dependence subscale scores $\geq 4$; and a $14 \%$ difference in prevalence of AUDIT problem subscale scores $\geq 1$.

\section{Ethics approval}

The study was approved by the University of Newcastle Human Research Ethics Committee (29 January 2009; no: H-20080432) and confirms to the principles embodied in the Declaration of Helsinki.

\section{RESULTS \\ Participants \\ Clubs}

Of the 328 potentially eligible clubs identified in the study area, 244 were deemed eligible following screening and invited to participate in the trial (see figure 1). Eighty-eight (36\%) consented to participate. Consenting clubs did not differ significantly from non-consenting clubs in terms of football code $\left(\chi^{2}=6.68, \quad \mathrm{df}=3 ; \mathrm{p}=0.08\right) \quad$ or location $\left(\chi^{2}=0.20, \mathrm{df}=1\right.$; $\mathrm{p}=0.66)$. Consenting clubs were randomly allocated to control $(\mathrm{N}=45)$ and intervention $(\mathrm{N}=43)$ conditions.

Club characteristics were similar across control and intervention groups, $80 \%$ were located in major city areas (table 2). Postintervention, $25(58 \%)$ of the 43 intervention group football clubs had completed the full intervention (level 3 accreditation). No significant differences were found between the percentage of clubs in the intervention and control groups that were lost to follow-up $(5 \%(n=2)$ vs $13 \%(n=6) ; p=0.16)$ (figure 1).

\section{Club members}

Prior to randomisation of clubs, baseline survey data were collected from 1411 club members (82\% consent rate; figure 1). At baseline, club members were on average $30+$ years of age; most were male and most were players (table 2).

\section{Primary outcome analysis}

Risky alcohol consumption at sporting clubs

As shown in table 3, at baseline, $25-27 \%$ of intervention and control club members reported consuming alcohol at risky levels at their club. At postintervention, 19\% of intervention club members reported consuming alcohol at such levels compared to $24 \%$ of control club members $(p=0.05)$. A sensitivity analysis imputing missing postintervention data with baseline figures found a similar intervention effect trend (postintervention: intervention $18 \%$ vs control group 22\%); however, this was not statistically significant $(p=0.10)$. Participation in risky alcohol consumption by members of Level-3 accredited 
Figure 1 Participant flow according to CONSORT reporting requirements.

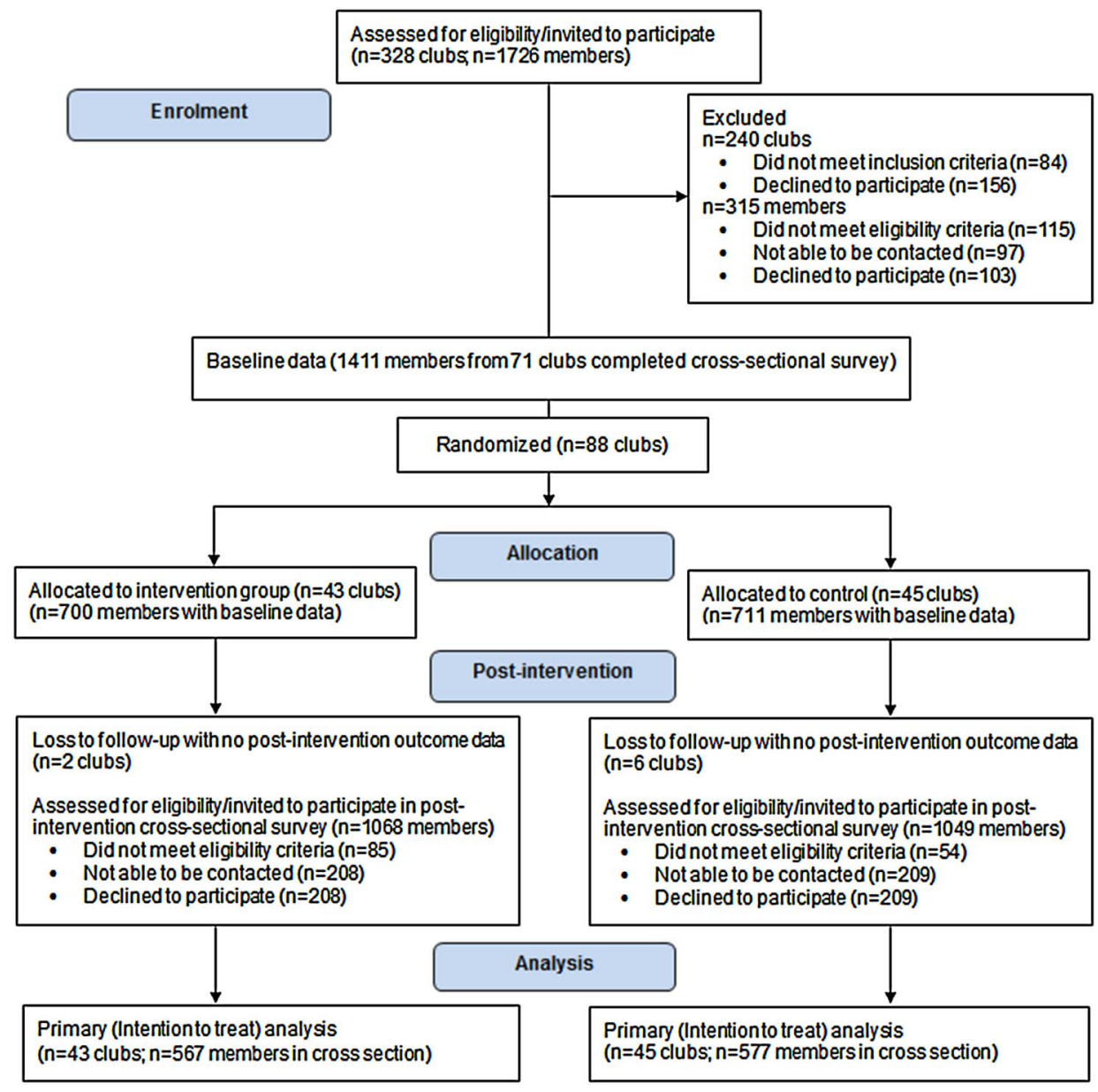

intervention clubs reduced from $31 \%$ at baseline to $20 \%$ postintervention.

Subgroup analyses found a significant intervention effect for clubs in inner/outer regional areas, with risky alcohol consumption reducing from $37 \%$ to $20 \%$ in such intervention clubs, compared to an increase from $19 \%$ to $32 \%$ in such control clubs (OR: 0.22 (95\% CI 0.09 to 0.59 ); p<0.01). In comparison, among the major city subgroups, the OR for the intervention effect was $\mathrm{OR}=0.74$ (95\% CI: 0.44 to $1.25 ; \mathrm{p}=0.26$ ). Among football codes, a significant intervention effect was found for soccer/association football clubs, with risky alcohol consumption reducing from $21 \%$ to $12 \%$ in such intervention clubs, compared with no change (15-16\%) among such control clubs (OR: 0.49 (95\% CI 0.23 to 1.03 ); $\mathrm{p}=0.06$ ). Among the other football code subgroups, ORs for intervention effect ranged from $\mathrm{OR}=0.54$ to $0.78(\mathrm{p}>0.05)$.

\section{Secondary outcome analysis}

Risk of alcohol-related harm

As shown in table 3, at baseline, the median total AUDIT score for intervention and control club members was 8 and 7, respectively. Postintervention, this score reduced to 6 for intervention club members compared to no change in the control group $(\mathrm{p}<0.01)$.

At baseline, 46-54\% of members of intervention and control group clubs reported a total AUDIT score of ' 8 or more'. Postintervention, this proportion was significantly lower in the intervention group (38\%) compared to the control group (45\%; $\mathrm{p}<0.01$, table 3$)$.
Statistically significant intervention effects were found for two of the three AUDIT subscales-consumption risk (postintervention: intervention group 47\%; control group 55\%; $\mathrm{p}<0.01$ ) and alcohol dependency risk (postintervention: intervention group $1 \%$; control group $4 \%$; $<<0.01)$.

\section{Random allocation and blinding}

Research staff collecting postintervention outcome data from club members correctly nominated the treatment status of the member's club just over half the time (53\%).

\section{DISCUSSION}

This is the first published randomised trial in any country to investigate the effect of an alcohol management intervention in modifying risky alcohol consumption and risk of alcohol-related harm among sports club members. The intervention resulted in an absolute reduction of $8 \%$ in risky alcohol consumption among members of sporting clubs in the intervention group, and a $37 \%$ differential reduction in the odds of risky drinking relative to the control group. A $16 \%$ absolute reduction in alcohol-related harm was also observed among members of intervention group clubs; a $42 \%$ differential reduction in the odds of such harm relative to the control group. Greater effect sizes were found for clubs in regional/rural areas compared to metropolitan areas, for soccer/association football clubs compared to other football codes, and for clubs that completed the full intervention according to protocol. Significant reductions in risk of alcohol dependence were also found. Given high participation rates in non-elite sports in high-income, low-income and 
Table 2 Baseline characteristics of participating football clubs and club members

\begin{tabular}{|c|c|c|}
\hline Characteristic & Control & Intervention \\
\hline (a) Clubs & $\mathrm{N}=45$ & $\mathrm{~N}=42^{*}$ \\
\hline \multicolumn{3}{|l|}{ Football code } \\
\hline Rugby league & $33.3 \%$ & $31 \%$ \\
\hline Rugby union & $26.7 \%$ & $33.3 \%$ \\
\hline Soccer/association football & $24.4 \%$ & $19 \%$ \\
\hline Australian rules football & $15.6 \%$ & $16.7 \%$ \\
\hline \multicolumn{3}{|l|}{ Geographical region } \\
\hline Major city & $80 \%$ & $83.3 \%$ \\
\hline Inner/outer regional & $20 \%$ & $16.7 \%$ \\
\hline \multicolumn{3}{|l|}{ Club size } \\
\hline Mean number of players (SD) & $272(235)$ & $259(360)$ \\
\hline (b) Members who participated in baseline survey & $\mathrm{N}=700$ & $\mathrm{~N}=711$ \\
\hline \multicolumn{3}{|l|}{ Club role } \\
\hline Players & $47 \%$ & $60.1 \%$ \\
\hline Spectator/other members & $18.3 \%$ & $13.9 \%$ \\
\hline Club committee members & $18.3 \%$ & $12.1 \%$ \\
\hline Coaches/umpires/referees & $16.5 \%$ & $13.9 \%$ \\
\hline \multicolumn{3}{|l|}{ Age of members } \\
\hline Mean (SD) & $32.7(12)$ & $36.0(11.9)$ \\
\hline \multicolumn{3}{|l|}{ Gender } \\
\hline Male & $87 \%$ & $77.4 \%$ \\
\hline \multicolumn{3}{|l|}{ Education } \\
\hline University educated & $23.2 \%$ & $21 \%$ \\
\hline \multicolumn{3}{|l|}{ Income } \\
\hline More than AU\$52 000 & $48 \%$ & $49.3 \%$ \\
\hline
\end{tabular}

middle-income countries ${ }^{7-9}$ and the prevalence of alcohol misuse by sports people, ${ }^{38} 39$ the intervention has the potential to contribute to reducing the risk of alcohol-related harm among the large numbers of sports' players, fans and officials.
Such a finding offers substantial advance evidence regarding the management of alcohol in public drinking venues and provides a non-enforcement policy option for governments seeking to reduce levels of alcohol-related harm in the community.

The positive study findings are consistent with those of previous non-controlled and cross-sectional studies of similar interventions in sports settings. ${ }^{16}{ }^{17}$ As the intervention in this study did not involve an enforcement element, to our knowledge this is the first randomised controlled trial to demonstrate the effectiveness an alcohol management intervention without enforcement. It is possible that the accreditation-based nature of the intervention acted to motivate a change in such practices, substituting the need for formal enforcement. ${ }^{32}$ While accreditationbased programmes for licensed premises have been operating for some time, such as Best Bar None in the UK, ${ }^{40}$ no controlled trials of such initiatives have been reported.

The observed reductions in overall risk of alcohol-related harm among club members (AUDIT measure) may indicate that a large proportion of risky alcohol consumption undertaken by members occurs within the club setting. If this is the case, then a reduction in drinking at the club, even without a reduction in drinking in other locations outside of the club, may reduce consumption and overall risk from drinking. Alternatively, the intervention may have independently influenced a change in members' alcohol use norms and behaviours outside of the sporting club setting. A further possible explanation is that the intervention may have persuaded members who were at-risk drinkers to leave the club or may have discouraged at-risk drinkers from joining the club. However, such displacement is considered less likely in sporting clubs than other licensed premises given that the primary and initial purpose of sports club attendance is to play or watch sport.

The results of the study should be considered in the context of its methodology. The internal validity of the study was strengthened by random assignment of clubs, blinding of data collection staff and analysis personnel and use of validated alcohol consumption outcome measures. The consent rate of

Table 3 Alcohol outcomes at baseline and postintervention, by treatment group

\begin{tabular}{|c|c|c|c|c|c|c|c|c|c|}
\hline & \multicolumn{3}{|l|}{ Baseline } & \multicolumn{3}{|c|}{ Postintervention } & \multirow[b]{3}{*}{$\begin{array}{l}\text { Adjusted OR } \\
(95 \% \mathrm{Cl})^{*}, t\end{array}$} & \multirow[b]{3}{*}{ ICC } & \multirow[b]{3}{*}{$\begin{array}{l}\text { Adjusted } \\
\text { p-valuet }\end{array}$} \\
\hline & \multirow[b]{2}{*}{$\begin{array}{l}\text { Control club } \\
\text { members }\end{array}$} & \multicolumn{2}{|c|}{$\begin{array}{l}\text { Intervention club } \\
\text { members }\end{array}$} & \multirow[b]{2}{*}{$\begin{array}{l}\text { Control club } \\
\text { members }\end{array}$} & \multicolumn{2}{|c|}{$\begin{array}{l}\text { Intervention club } \\
\text { members }\end{array}$} & & & \\
\hline & & All & $\begin{array}{l}\text { Level three } \\
\text { clubsł }\end{array}$ & & All & $\begin{array}{l}\text { Level three } \\
\text { clubsł }\end{array}$ & & & \\
\hline \multicolumn{10}{|l|}{ Graduated frequency index } \\
\hline $\begin{array}{l}\text { Consumption of } 5 \text { or more } \\
\text { drinks at least once a } \\
\text { month at the club }\end{array}$ & $175(25 \%)$ & $191(27 \%)$ & $120(31 \%)$ & $138(24 \%)$ & $106(19 \%)$ & $76(20 \%)$ & $0.63(0.40$ to 1.00$)$ & 0.18 & 0.05 \\
\hline \multicolumn{10}{|l|}{ Overall AUDIT } \\
\hline Median (min, max) & $7(0,26)$ & $8(0,28)$ & $8(0,28)$ & $7(0,25)$ & $6(0,26)$ & $6(0,26)$ & - & 0.15 & $<0.01$ \\
\hline Score $\geq 8$ & $330(46 \%)$ & $374(54 \%)$ & $213(56 \%)$ & $259(45 \%)$ & $218(38 \%)$ & $132(35 \%)$ & $0.58(0.38$ to 0.87$)$ & 0.17 & $<0.01$ \\
\hline \multicolumn{10}{|l|}{ AUDIT subscales } \\
\hline $\begin{array}{l}\text { Alcohol consumption } \\
\text { subscale (score } \geq 6 \text { ) }\end{array}$ & $402(57 \%)$ & $429(61 \%)$ & $240(63 \%)$ & $314(55 \%)$ & $265(47 \%)$ & $167(45 \%)$ & $0.60(0.41$ to 0.87$)$ & 0.13 & $<0.01$ \\
\hline $\begin{array}{l}\text { Alcohol dependence } \\
\text { subscale (score } \geq 4 \text { ) }\end{array}$ & $19(3 \%)$ & $25(4 \%)$ & $12(3 \%)$ & $22(4 \%)$ & $6(1 \%)$ & $5(1 \%)$ & $0.20(0.06$ to 0.65$)$ & 0.12 & $<0.01$ \\
\hline $\begin{array}{l}\text { Alcohol-related problems } \\
\text { subscale (score } \geq 1 \text { ) }\end{array}$ & $340(48 \%)$ & $378(54 \%)$ & $214(56 \%)$ & $259(45 \%)$ & $234(41 \%)$ & $142(38 \%)$ & $0.67(0.43$ to 1.03$)$ & 0.12 & 0.07 \\
\hline
\end{tabular}


$36 \%$ has the potential to limit the external validity of the findings; however, the likelihood of this is mitigated by the absence of differences between consenting and non-consenting clubs in terms of football code or location, and the consistently positive intervention effects across subgroups according to club type and location. A previous non-controlled study of the intervention with sports, including cricket, was also suggestive of a positive effect. ${ }^{17}$ In addition, over 6500 sport clubs across Australia have adopted the Good Sports programme, ${ }^{28}$ suggesting that a significant number of clubs are willing to adopt alcohol management practice interventions. While the results of the sensitivity analysis, which adopted a conservative imputation approach, also trended toward a positive intervention effect for risky drinking, this finding was not statistically significant $(p=0.1)$ and further studies are required to confirm these findings.

It would be of benefit for further research to assess the impact of the intervention on club revenue and membership given these are priority outcomes for community sporting clubs; so would be the collection of data on additional measures of alcohol-related harm such as drink driving and violence. Investigation into the mediators of intervention effectiveness may also help identify the elements of the intervention that had the most influence on changing drinking behaviours and this will assist in streamlining the intervention for future adoption by sports clubs.

\section{What is already known on this subject?}

Higher than average levels of risky alcohol consumption and alcohol-related harm occur among people involved in sport. While sports clubs and venues represent opportune settings to implement strategies to reduce such risks, no randomised controlled trials have been reported.

\section{What this study adds?}

Non-enforcement-based alcohol management interventions within sports clubs have the potential to reduce risky alcohol consumption by club members and the overall risk of alcohol-related harm. With a large number of people across the globe involved with sporting clubs, there is the potential for such intervention to play an important role in contributing to community-based alcohol harm reduction.

Acknowledgements The research team would like to acknowledge the support of the project staff involved in coordinating and delivering the intervention to participating clubs, in particular Amy Richardson, Marc Glanville and Kylie Young and the interviewers involved in collecting outcome data from club management representatives and club members.

Contributors MK led the drafting of the manuscript. LW, JT, BCR, KEG, JCR, PME, $\mathrm{JHW}$ and MK were involved in the conception of the research question and design of the study. LW, JT, MK, BCR, KEG, PD, MNS and IC were involved in the intervention design and implementation. $C L, P M E$ and MK undertook the analysis of data. All authors reviewed drafts of the manuscript and contributed to its completion. All authors approved the final version of the manuscript.

Funding The trial was funded by the Australian Research Council under the Linkage Projects scheme (grant number LP0989386, http://www.arc.gov.au).

Competing interests This study was funded by the Australian Research Council, Hunter New England Population Health and the Australian Drug Foundation.
Ethics approval The University of Newcastle Human Research Ethics Committee (29 January 2009; no: H-2008-0432).

Provenance and peer review Not commissioned; externally peer reviewed.

Open Access This is an Open Access article distributed in accordance with the Creative Commons Attribution Non Commercial (CC BY-NC 4.0) license, which permits others to distribute, remix, adapt, build upon this work non-commercially, and license their derivative works on different terms, provided the original work is properly cited and the use is non-commercial. See: http://creativecommons.org/ licenses/by-nc/4.0/

\section{REFERENCES}

1 World Health Organisation. Global status report on alcohol and health 2014. Geneva: World Health Organisation, 2014.

2 Merlo LJ, Hong J, Cottler LB. The association between alcohol-related arrests and college football game days. Drug Alcohol Depend 2010;106:69-71.

3 Lawson JS, Evans AR. Prodigious alcohol consumption by Australian rugby league footballers. Drug Alcohol Rev 1992;11:193-5.

4 O'Farrell A, Allwright $S$, Kenny $S$, et al. Alcohol use among amateur sportsmen in Ireland. BMC Res Notes 2010:3:313.

5 Bedendo A, Opaleye ES, Andrade ALM, et al. Heavy episodic drinking and soccer practice among high school students in Brazil: the contextual aspects of this relationship. BMC Public Health 2013;13:247.

6 National Health and Medical Research Council. Australian guidelines to reduce health risks from drinking Alcohol. Canberra: Commonwealth of Australia, 2009.

7 International Federation of Association Football. Big Count http://www.fifa.com/ worldfootball.bigcount/index.html (accessed May 2014).

8 Australian Bureau of Statistics. Sport and recreation: a statistical overview. Canberra: Commonwealth of Australia, 2009.

9 Sport England. How people are involved in sport-the national picture http://www. sportengland.org/research/who-plays-sport/national-picture/ how-do-people-play-sport-in-england/ (accessed August 2013).

10 UK Premier League. Premier League: attending a match. http://www.premierleague. com/content/premierleague/en-gb/fans/attending-a-match.html (accessed June 2012)

11 Lenk KM, Toomey TL, Erickson DJ, et al. Alcohol control policies and practices at professional sports stadiums. Public Health Rep 2010;125:665-73.

12 Lyne M, Galloway A. Implementation of effective alcohol control strategies is needed at large sports and entertainment events. Aust N Z J Public Health 2012;36:55-60.

13 Priest N, Armstrong R, Doyle J, et al. Policy interventions implemented through sporting organisations for promotiong healthy behaviour change. Cochrane Database Syst Rev 2008;(3):CD004809.

14 Martens MP, Dams-O'Connor K, Beck NC, et al. A systematic review of college student-athlete drinking: prevalence rates, sport-related factors, and interventions. $J$ Subst Abuse Treat 2006;31:305-16.

15 Martineau F, Tyner $E$, Lorenc $T$, et al. Population-level interventions to reduce alcohol-related harm: an overview of systematic reviews. Prev Med 2013:57:278-96.

16 Mentha R, Wakerman J. An evaluation of the Australian Football League Central Australian Responsible Alcohol Strategy 2005-07. Health Promot J Austr 2009;20:208-13.

17 Rowland B, Allen F, Toumbourou JW. Association of risky alcohol consumption and accreditation in the 'Good Sports' alcohol management programme. Epidemiol Community Health 2012;66:684-90.

18 Wolfenden L, Kingsland M, Rowland B, et al. Addressing alcohol use in community sports clubs: attitudes of club representatives. Aust N Z J Public Health 2012;36:93-4.

19 Dietze PM, Fitzgerland JL, Jenkinson RA. Drinking by professional Australian Football League (AFL) players: prevalence and correlates of risk. Med J Australia 2008;189:479-83.

20 Kingsland $\mathrm{M}$, Wolfenden $\mathrm{L}$, Rowland B, et al. Alcohol consumption and sport: a cross-sectional study of alcohol management practices associated with at-risk alcohol consumption at community football clubs. BMC Public Health 2013;13:762.

21 Grossbard J, Geisner IM, Neighbors C, et al. Are drinking games sports? College athlete participation in drinking games and alcohol-related problems. I Stud Alcohol 2007:68:97-105

22 Toomey TL, Erickson DJ, Lenk KM, et al. Likelihood of illegal alcohol sales at professional sport stadiums. Alcohol Clin Exp Res 2008;32:1859-64.

23 O'Brien KS, Lynott D, Miller PG. Alcohol industry sponsorship and alcohol-related harms in Australian university sportspeople/athletes. Drug Alcohol Rev 2013;32:241-7

24 Barbor T, Caetano R, Casswell S, et al. Alcohol: no ordinary commodity-research and public policy. Oxford: Oxford University Press, 2010

25 National Drug Research Institute. Restrictions on the sale and supply of alcohol: evidence and outcomes. Perth: National Drug Research Insitute, Curtin University of Technology, 2007 
26 Kingsland $\mathrm{M}$, Wolfenden $\mathrm{L}$, Rowland $\mathrm{BC}$, et al. A cluster randomised controlled trial of a comprehensive accreditation intervention to reduce alcohol consumption at community sports clubs: study protocol. BMJ Open 2011;1:bmjopen-2011-000328.

27 Battaglia $M$, Link $M$, Frankel $M$, et al. An evaluation of respondent selection methods for household mail surveys. Public Opin Q 2008;72:459-69.

28 Rowland B, Allen F, Toumbourou J. Impact of alcohol harm reduction strategies in community sports clubs: pilot evaluation of the good sports program. Health Psychol 2012;31:323-33.

29 New South Wales Health. A Framework for Building Capacity to Improve Health. http://www0.health.nsw.gov.au/pubs/2001/pdf/framework_improve.pdf (accessed June 2010).

30 Rohrbach LA, Grana R, Sussman S, et al. Type II translation: transporting prevention interventions from research to real-world settings. Eval Health Prof 2006;29:302-33.

31 Greenhalgh T, Robert G, Macfarlane F, et al. Diffusion of innovations in service organizations: systematic review and recommendations. Milbank Q 2004;82:581-629.

32 Pomey MP, Lemieux-Charles L, Champagne F, et al. Does accreditation stimulate change? A study of the impact of the accreditation process on Canadian healthcare organizations. Implement Sci 2010;5:31.
33 Bero LA, Grilli R, Grimshaw JM, et al. Closing the gap between research and practice: an overview of systematic reviews of interventions to promote the implementation of research findings. BMJ 1998;317:465-8.

34 Ivers $\mathrm{N}$, Jamtvedt $\mathrm{G}$, Flottorp $\mathrm{S}$, et al. Audit and feedback: effects on professional practice and healthcare outcomes. Cochrane Database Syst Rev 2012;2012: CD000259.

35 Greenfield TK. Ways of measuring drinking patterns and the difference they make: experience with graduated frequencies. J Subst Abuse 2000;12:33-49.

36 Conigrave K, Saunders J, Reznik R. Predictive capacity of the AUDIT questionnaire for alcohol-related harm. Addiction 1995;90:1479-85.

37 Hanley JA, Negassa A, Edwardes MDD, et al. Statistical analysis of correlated data using generalized estimating equations: an orientation. Am J Epidemiol 2003; 157:364-75.

38 Nelson TF, Wechsler H. Alcohol and college athletes. Med Sci Sports Exerc 2001;33:43-7.

39 O'Brien KS, Kolt GS, Martens MP, et al. Alcohol-related aggression and antisocial behaviour in sportspeople/athletes. J Sci Med Sport 2012;15:292-7.

40 Best Bar None. Best Bar None UK. http://www.bbnuk.com/ (accessed April 2013). 